\title{
MUDANÇAS DE PARADIGMAS NA FILARIOSE BANCROFTIANA
}

Gerusa Dreyer ${ }^{* 1}$, Denise Mattos ${ }^{2}$, José Figueredo-Silva ${ }^{3}$, Joaquim Norões ${ }^{4}$

Trabalho realizado na Organização Não-Governamental Amaury Coutinho para Doenças Endêmicas Tropicais, Recife, PE

\section{*Correspondência:}

ONG Amaury Coutinho

Rua Conselheiro Portela, 665,

Sala 120 ,

CEP 52020-030, Recife - PE

Fax/Fone: +558134426195

dreyer-g@uol.com.br

\section{RESUMO}

Ao longo do tempo, a maneira como se entende um determinado assunto passa por modificações através da pesquisa científica. Na maioria das vezes, essas mudanças causam pequenas diferenças na estrutura total do tópico em questão. Outras vezes, entretanto, ocorrem mudanças revolucionárias que não só alteram a compreensão do assunto em si, mas promovem a abertura de diferentes perspectivas que podem desencadear o início de novas etapas de interpretações e de novos caminhos de conhecimento. Exemplo disso foram os estudos de Gregor Johann Mendel que levaram à descoberta de leis da hereditariedade que, por sua vez, revolucionaram a biologia e traçaram as bases da genética. Em algumas situações, as mudanças não só modificam a forma de pensar, mas também têm implicações práticas ao melhorar a qualidade de vida de muitos seres humanos. No seu livro A Estrutura de Revoluções Científicas, Thomas Kuhn se refere às ruturas nessa evolução científica como "mudanças de paradigma", um termo que hoje é usado de uma forma genérica para descrever uma modificação profunda em nossos pontos de referência. O paradigma de que o estágio adulto da Wuchereria bancrofti causava a obstrução do vaso linfático e desencadeava uma reação imunológica inevitável em indivíduos predispostos, provocando a elefantíase, foi substituído pela esperança de que ser infectado não mais significa, necessariamente, ser um potencial portador da forma mais deformante da disfunção linfática. A infecção bacteriana secundária de repetição (semelhante clinicamente à erisipela) é hoje reconhecida como o fator mais importante para a instalação e a progressão do linfedema crônico, nos indivíduos que vivem em áreas endêmicas de filariose linfática. Evitar ou minimizar os episódios agudos bacterianos é um processo factível para a maioria dos habitantes das comunidades endêmicas, através do uso regular de água e sabão: a forma mais simples de higiene já conhecida pelo ser humano.

Unitermos: Elefantíase filarial. Wuchereria bancrofti. Wolbachia. Linfedema. Paradigma. Clubes da Esperança.

\section{INTRODUÇÃO}

Ainda que novos conhecimentos tenham recentemente substituído dogmas antigos, e outros avanços importantes tenham surgido ao longo dos tempos, a infecção filarial linfática e as suas complicações ainda permanecem endêmicas em 83 países $^{1}$, dentre os quais a Índia tem o maior número de infectados. As Américas Central e do Sul, juntas, são responsáveis por um percentual de $0,3 \%$ em relação à população endêmica mundial, e o Haiti se apresenta como o país de maior prevalência. No Brasil, as áreas endêmicas estão localizadas em dois bairros de Maceió (AL) (Jacintinho e Feitosa) e e no Grande Recife (Recife, Jaboatão, Olinda, Paulista e Cabo) ${ }^{3}$, sendo Jaboatão dos Guararapes e Olinda consideradas os focos de maior transmissibilidade ${ }^{4}$. Belém do Pará, que já foi considerado o maior foco endêmico do Brasil, parece ter interrompido a transmissão desde a década de $1990^{5}$.

O termo filariose linfática - também conhecida por elefantíase - reúne as filarioses brugiana e bancroftiana, transmitidas por mosquitos. A brugiana é a infecção pelas Brugia malayi e B. timori, encontradas em forma endêmica apenas na Ásia. Em contraste com a bancroftose, causada pela Wuchereria bancrofti, a doença crônica do sistema gênito-urinário (quilúria, hidrocele e quilocele) não existe na filariose brugiana. Segundo a Organização Mundial da Saúde (OMS), há uma estimativa de que existem 120 milhões de pessoas portadoras de microfilaremia (100 milhões com bancroftose e 20 milhões infectadas pelas Brugias) e mais de 900 milhões vivendo sob risco de adquirir a infecção $0^{6}$. Estima-se a existência de um número global de 40 milhões de pacientes portadores das duas formas crônicas mais prevalentes da doença: a hidrocele e o linfedema ${ }^{6}$. Desse total, cerca de 16 milhões são portadores de linfedema ${ }^{7}$. A Índia, sozinha, é responsável por mais de sete milhões desses casos ${ }^{8}$.

\section{As grandes mudanças}

O entendimento das manifestações clínicas da filariose bancroftiana mudou muito com o surgimento de novos

1. Consultora da Organização Não-Governamental Amaury Coutinho para Doenças Endêmicas Tropicais, Recife, PE

2. Assistente Social do Serviço Social, Hospital das Clínicas, Universidade Federal de Pernambuco, Recife, PE

3. Professor Adjunto de Patologia - Núcleo de Ensino e Pesquisa em Patologia - Faculdade de Ciências Médicas - FACIME - Universidade Estadual do Piauí, Teresina, PI

4. Professor Adjunto de Urologia, Departamento de Cirurgia, Centro de Ciências da Saúde, UFPE, Recife, PE 
conhecimentos acumulados nos últimos 15 anos. Neste trabalho de revisão, será dada ênfase às alterações no vaso linfático e no linfonodo (chamadas de manifestações linfáticas). As manifestações extralinfáticas causadas pelas microfilárias podem ser encontradas em artigo de revisão que inclui a descrição em detalhes da forma respiratória rara chamada de eosinofilia pulmonar tropical ${ }^{9}$.

A utilização de duas ferramentas de diagnóstico em filariose bancroftiana contribuiu sobremodo para a geração de novos conhecimentos dessa parasitose. Através da utilização da linfocintigrafia pôde-se estudar, de forma não-invasiva, os vasos linfáticos de membros inferiores identificando-se alterações morfológicas precoces em pacientes infectados, porém assintomáticos ${ }^{10}$. Ao mesmo tempo, foi possível rever os conceitos de anormalidade/ normalidade da morfologia de vasos linfáticos, quando indivíduos endêmicos e não endêmicos foram estudados pela mesma metodologia ${ }^{11}$. Já a ultrassonografia, usada de forma pioneira no Brasil em pacientes com bancroftose, possibilitou visualizar/localizar os vermes adultos vivos no seu habitat, o que ficou conhecido pelo sinal da dança da filária ou SDF (Figura $1 A)^{12}$. Sem dúvidas esse fato possibilitou a maior mudança de paradigma na filariose bancroftiana: o substrato anatomopatológico da doença deixou de seguir o conceito clássico de que a obstrução causada pelos parasitos adultos, vivos ou mortos, ao impedir o fluxo da linfa, era a responsável pela dilatação do segmento do vaso linfático abaixo da mesma. Compreendeu-se, então, que a linfangiectasia na bancroftose é de causa não-obstrutiva ${ }^{13,14,15}$. Isso possibilitou muitos desdobramentos importantes na compreensão da relação hóspede-hospedeiro que serão comentados adiante.

O reconhecimento da existência de duas síndromes agudas distintas em pacientes residentes em área endêmica de bancroftose foi um marco na reavaliação da fisiopatogenia do linfedema. A primeira é decorrente da morte do verme adulto no vaso linfático ou em linfonodo - denominada linfangite filarial aguda (LFA) e adenite filarial aguda, respectivamente. A segunda, de maior prevalência (acomete 97\% dos indivíduos) é causada pela infecção da pele por bactérias piogênicas - clinicamente semelhante à erisipela ${ }^{16}$, chamada de dermatolinfoangioadenite aguda (DLAA) ${ }^{17}$. As infecções bacterianas secundárias de repetição seriam as responsáveis pela instalação e pela progressão do linfedema crônico, outrora atribuídas à obstrução linfática pelo parasita. Outro aspecto foi o esclarecimento de que a patogênese da hidrocele aguda é resultante da obstrução aguda e temporária dos vasos linfáticos de conteúdo escrotal pela formação do granuloma filarial decorrente da morte dos vermes adultos. Essa é a única manifestação clínica que resulta de obstrução linfática, porém sempre transitória, devido à recanalização dos vasos e à reabsorção dos granulomas ${ }^{14}$. Isso resulta, a curto prazo, na reversão dessas hidroceles agudas, na maioria das vezes. A partir desses entendimentos, alguns fatores (como a
Figura 1 - A figura $A$ exibe a ultrassonografia do conteúdo escrotal com sonda de 7,5 MHz. Em modo $B$ (à esquerda), vaso linfático dilatado contendo pontos e segmentos lineares ecogênicos no interior de sua luz (setas). Em tempo real, as estruturas ecogênicas mostram movimento ativo peculiar chamado de sinal da dança da filária (SDF), o que corresponde à presença de vermes adultos vivos de W. bancrofti no interior de vasos linfáticos; à direita, em modo $M$, visualiza-se o registro gráfico do SDF (setas). A figura B mostra o teste imunocromatográfico (positivo) feito com sangue capilar. A figura C mostra lesão interdigital (seta), no quarto espaço interdigital de membro inferior esquerdo, considerada a porta de entrada mais importante nos portadores de linfedema (Dreyer et al. 2006)

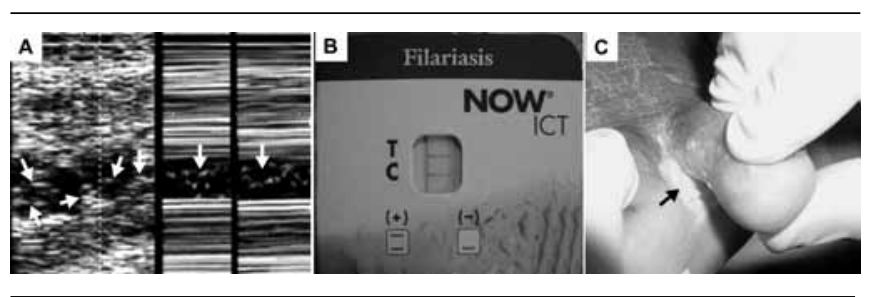

extensão e a severidade da dilatação linfática) foram adicionados para o esclarecimento posterior da hidrocele crônica, uma vez que não depende diretamente da etapa obstrutiva na fase aguda do processo ${ }^{18}$

A presença de dano linfático (representado pela linfangiectasia) em indivíduos assintomáticos portadores de vermes adultos vivos foi identificada, e a definição clássica do grupo de pacientes assintomáticos infectados (microfilarêmicos ou não) foi revista e foi possivel mostrar que esses indivíduos já são portadores, no mínimo, de doença subclínica ${ }^{13}$, fato não cogitado no passado. A dilatação linfática progride enquanto o verme adulto permanece vivo, e a velocidade dessa progressão foi determinada pela ultrassonografia, em média de 1,2 $\mathrm{mm}$ por ano, embora ocorra uma grande variação de progressão da doença entre diferentes pacientes e entre diferentes vasos linfáticos de um mesmo paciente ${ }^{19}$. Identificou-se a presença de duas subpopulações de vermes adultos em relação ao efeito adulticida da dietilcarbamazina (DEC), que classifica os parasitos como sensíveis e nãosensíveis, e que essa resposta é dose-independente a partir de $6 \mathrm{mg} / \mathrm{kg}$ em dose única ${ }^{20}$. Isso possibilitou, entre outras coisas, a base científica para a dose única preconizada no tratamento em massa e no tratamento individual, assim como o entendimento de que, em alguns indivíduos, o reaparecimento de microfilaremia não era devido a reinfecções.

O conjunto de novas informações ajudou a entender melhor a relação hóspede-hospedeiro e demonstrou a imensa capacidade de o organismo humano compensar o dano linfático produzido diretamente pelo parasito. Assim, tornou-se claro que um

\footnotetext{
É uma doença infecciosa aguda de pele, com inflamação secundária dos linfáticos e linfonodos que drenam a área afetada. É caracterizada por uma área bem definida de inflamação cutânea, com hiperemia, edema agudo e dor. É acompanhada por linfangite ascendente ou adenite satélite ipsilateral. Febre, calafrios, cefaléia, prostração e outras manifestações sistêmicas de bacteremia são comuns durante esses episódios.

*Dois testes estão comercialmente disponiveis para o diagnóstico individual: (1) o teste quantitativo ELISA Og4C3, que utiliza soro, e para a captura é usado um anticorpo monoclonal, gerado a partir da Onchocerca gibsoni. (2) o teste imunocromatográfico (ICT), qualitativo, com leitura em 10 minutos que pode ser feito com sangue capilar ou venoso, soro ou plasma. O ICT também é recomendado pela OMS para a avaliação do tratamento em massa das regiões endêmicas, que tem como alvo a interrupção da transmissão.

**A DEC é derivada da piperazina, distribuída no Brasil pela Fundação Nacional de Saúde e fabricada por Farmanguinhos - Fiocruz. É apresentada em comprimidos de 50mg do sal citratado.

*** A ivemerctina está comercializada no Brasil pela Ucifarma (Ivermectil $($ ); Cirfarma (Vermectil@) e SolvayFarma (Revectina $($ ). É apresentada em comprimidos de $6 \mathrm{mg}$.
} 
conjunto de fatores, agindo de forma simultânea e/ou sequenciada, é necessário para produzir doença clínica. Nessa linha de raciocínio, em 2000, Dreyer et al. ${ }^{15}$ propuseram um modelo em que o aparecimento de doença clínica (aguda ou crônica) em área endêmica de bancroftose é multifatorial na sua origem (Diagrama). Esse modelo tem base principalmente clínica, substanciada pelas lições aprendidas de forma transdisciplinar com os achados ultrassonográficos, cirúrgicos, histopatológicos, farmacológicos e quimioterápicos ${ }^{15}$. Essa mudança de paradigma no entendimento da doença bancroftiana contribuiu, sobremodo, para que se revisassem as condutas terapêuticas nas diferentes formas de apresentação clínica dos pacientes que vivem em áreas endêmicas de filariose linfática.

\section{O diagnóstico e as complicações}

O diagnóstico da doença bancroftiana se baseia, eminentemente, no diagnóstico clínico. Até o momento, não existe nenhum teste marcador de doença clínica linfática de origem filarial. Intrigante ainda é o binômio infecção filarial vs doença crônica. A presença da microfilaremia nos pacientes é oposta nas duas maiores expressões clínicas da doença: a hidrocele e o linfedema. No primeiro caso, o mapeamento da prevalência de hidrocele em uma determinada área se correlaciona tão positivamente com a prevalência de microfilaremia, que é recomendada como um teste rápido de investigação da endemicidade em uma dada comunidade ${ }^{21}$. Assim, nos portadores de fluido em cavidade vaginal testicular (hidrocele e quilocele), a probabilidade de infecção ativa é alta e deve-se, de rotina, solicitar a investigação parasitológica. Por outro lado, os testes disponíveis, atualmente, para o diagnóstico de infecção ativa - pesquisa de microfilária em sangue periférico, pesquisa de antígeno secretório-excretório circulante*, verme adulto relacionado (Figura $1 \mathrm{~B}$ ) e identificação dos movimentos da $W$. bancrofti através do SDF observados pela ultrassonografia - não possuem sensibilidade de $100 \%$, seja de forma isolada ou mesmo combinada ${ }^{22-25}$. Isso é particularmente importante para a população masculina adulta jovem com ou sem sintomatologia ${ }^{13}$, pois, mesmo com testes parasitológicos negativos, pode estar indicado o tratamento antifilarial com a $\mathrm{DEC}^{* *}$ em dose única de $6 \mathrm{mg} / \mathrm{kg}$, ponderando-se os dados epidemiológicos, tais como a prevalência da infecção na área da qual o indivíduo é originário, o seu tempo de residência, as condições em que vive e se já fez tratamento antifilarial e há quanto tempo. Por outro lado, nos portadores de linfedema, a identificação de infecção ativa é um fenômeno muito raro. Isso é importante para se ponderar a necessidade da investigação de infecção ativa e da indicação do tratamento antifilarial nas condutas propostas em áreas endêmicas pelos serviços que recebem usualmente esses pacientes. Assim, nos pacientes portadores de linfedema, a pesquisa de infecção ativa não deverá fazer parte do protocolo de investigação de rotina. Em consequência, a indicação de tratamento antifilarial nos portadores dessa manifestação acontece raramente ${ }^{16,26}$. Até o momento, duas drogas são recomendadas para o tratamento da filariose linfática: a ivermectina e a DEC. A ivermectina***, droga revolucionária no tratamento de onchocercose e da filariose linfática, tem ação exclusivamente microfilaricida ${ }^{27,28} \mathrm{e}$ não está indicada para o tratamento individual, quando o alvo

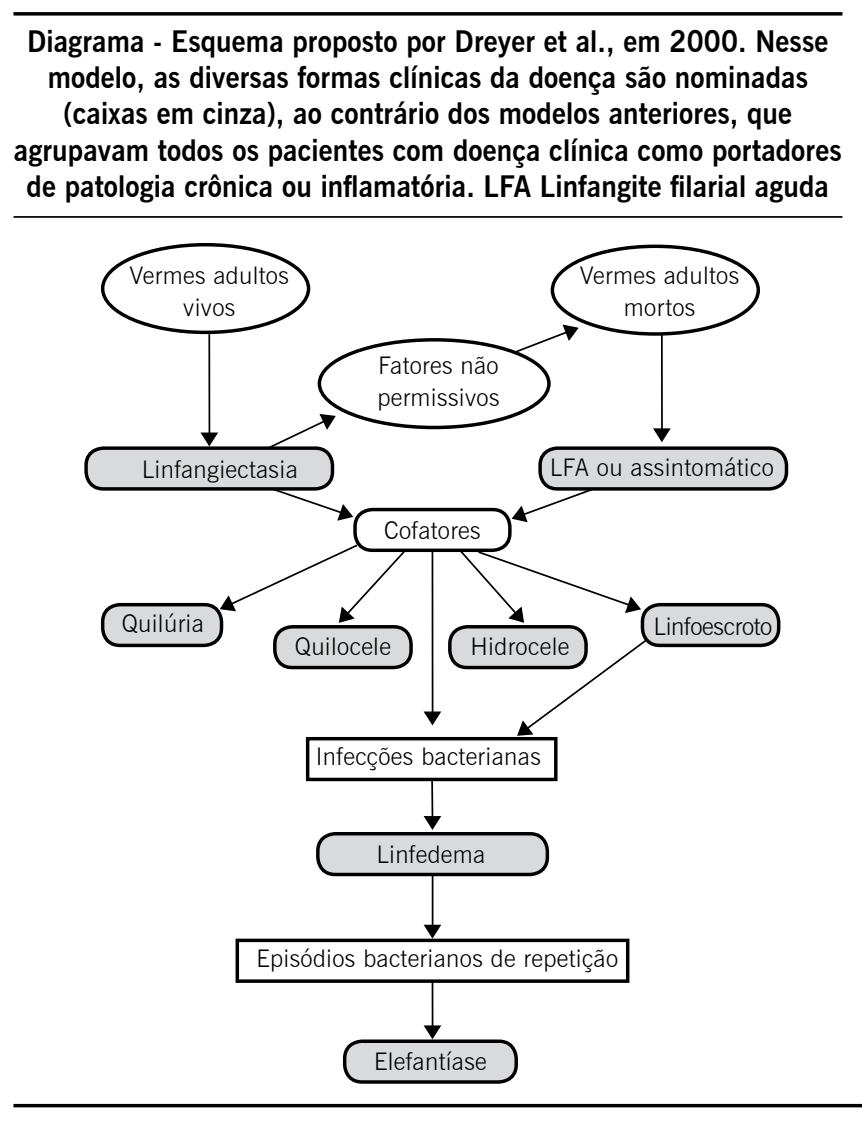

principal é o verme adulto. A ivermectina na dose de $150 \mu \mathrm{g} /$ kg (combinada com o albendazol - 400) faz parte do protocolo anual de tratamento em massa recomendado pela OMS (Programa Global de Eliminação da Filariose Linfática) para o controle da transmissão para países onde co-existem a Loa loa e/ou a Onchocerca volvulus. O tratamento com a DEC está contraindicado pela severidade das reações adversas causadas pela morte das microfilárias de $L$. loa e de 0 . volvulus no sistema nervoso central e nos olhos/pele, respectivamente. Nas demais áreas endêmicas está recomendado o tratamento em massa com a DEC (6mg/kg), co-administrada com o albendazol (400mg), em dose única anual ${ }^{29}$. Para o tratamento individual, a DEC ainda é a droga de escolha e é recomendado o seu uso em dose única visando a morte do verme adulto ou por 12 dias $(6 \mathrm{mg} / \mathrm{kg}$ ) para efeito microfilaricida a curto prazo, como no caso de pacientes portadores da eosinofilia pulomonar tropical ${ }^{9}$ e de hematúria filarial ${ }^{30}$.

Há evidências de que o local de predileção do parasito adulto vai depender da idade do indivíduo, no momento em que ocorrem as primeiras interações entre hóspede e hospedeiro. Nas áreas endêmicas é de se esperar que, logo na primeira infância, os indivíduos sejam expostos às larvas infectantes. A linfadenopatia indolor (sem linfedema ipsilateral) parece ser a forma predominante da expressão clínica da doença em crianças e adolescentes $24,31,32$. Assim, na população endêmica, - linfonodo periférico seria a primeira estação de parada e de "estabelecimento do acordo imunológico para a sobrevivência 
do parasito". Após a puberdade, o local de predileção passaria a ser os linfáticos intraescrotais, na população masculina ${ }^{33,34}$, e os linfáticos periféricos dos membros superiores, inferiores e mama, na população feminina ${ }^{16,35,36}$. De interesse é a possibilidade de acometimento de adenopatia filarial em indivíduos adultos que migram de áreas não-endêmicas para as endêmicas, ratificando ser o linfonodo o primeiro local de interação com o parasita ${ }^{37,38}$.

De uma maneira simplificada, a apresentação clínica da filariose bancroftiana diretamente relacionada ao verme adulto pode ser classificada em formas agudas e crônicas. As formas agudas são produzidas pela morte do parasito adulto e, dependendo da localização dos vermes, se em linfonodo ou em vaso linfático, podem provocar episódios de adenites ou linfangites, respectivamente. Em pacientes adultos do sexo masculino, dependendo da localização do parasito no linfático intraescotal em relação à rede de drenagem da túnica vaginal, a morte do verme pode provocar hidrocele aguda, que, habitualmente, é leve e reversível em cerca de $80 \%$ dos casos. 0 paciente geralmente não percebe os episódios de formação do granuloma filarial que caracteriza a morte de verme adulto ${ }^{14}$. A reação é clinicamente silenciosa em cerca de $50 \%$ dos casos. Na outra metade sintomática, o processo é referido como uma leve dor ou apenas um desconforto testicular. Em todos os casos, a reação inflamatória se restringe à área do granuloma; não existe um quadro de epididimite, funiculite ou orquite ${ }^{18}$, como descrito na literatura mais antiga ${ }^{39,40}$. Não existem também repercussões sistêmicas, como febre. Em mulheres adultas, quando há o processo de linfangite (sempre retrógrada), dificilmente ocorre a formação de linfedema agudo do membro ipsilateral e, quando acontece, é reversível, não resultando em linfedema crônico ${ }^{15}$. As formas crônicas da bancroftose em adultos são representadas basicamente pela linfangiectasia não-obstrutiva que, na grande maioria dos indivíduos, é subclínica ${ }^{13}$, pela quilúria ${ }^{41}$ e pelo acúmulo de fluido em túnica vaginal testicular ${ }^{18}$. Como já referido, em crianças de ambos os sexos, a forma crônica mais comum é a adenopatia indolor.

O melhor conhecimento da relação hóspede-hospedeiro contribuiu sobremodo para que se revisassem as condutas terapêuticas em áreas endêmicas. A modificação terapêutica mais dramática ocorreu entre os pacientes portadores de linfedema, tanto em áreas de Brugia ${ }^{42,43}$ quanto nas de Wuchereria ${ }^{44}$. 0 conceito antigo era o de que a doença progrediria inexoravelmente, uma vez que seria dependente da resposta imunológica do hospedeiro ao parasito, e muito pouco ou nada poderia ser feito pelo paciente. Observou-se, entretanto, que o substrato anatomopatológico da doença causada pela filariose linfática - a linfangiectasia não-obstrutiva - poderia predispor a uma disfunção linfática que induziria uma maior susceptibilidade para a presença de lesões interdigitais nos membros afetados, o que aumentaria o risco de infecções bacterianas secundárias da pele. Esse processo infeccioso/inflamatório agudo bacteriano (DLAA), independentemente da presença de infecção ativa filarial, levaria a uma maior disfunção do sistema linfático local, formando-se, assim, um círculo vicioso: linfangiectasia, disfunção linfática, predisposição a portas de entrada (Figura 1C) e consequentes infecções bacterianas agudas que, por sua vez, produziriam mais lesão linfática. Quanto maior a lesão linfática (isto é, a gravidade do linfedema), maior a probabilidade de novos episódios agudos bacterianos, e assim sucessivamente ${ }^{15,45}$. Dessa forma, o "linfedema filarial", na realidade, é hoje considerado como uma complicação dos episódios agudos bacterianos apresentados pelos pacientes. Portanto, o portador de linfedema crônico "de etiologia filarial" deve ser, então, conduzido com o mesmo protocolo geral utilizado para o portador de linfedema de outras etiologias, centrado especialmente na prevenção dos episódios agudos bacterianos de repetição e uso de medidas fisioterápicas para se postergar ou mesmo se evitar a progressão para a elefantíase. Isso é igualmente válido para os pacientes procedentes de áreas endêmicas atendidos em áreas não-endêmicas. A conduta terapêutica mais importante durante o episódio agudo bacteriano é o conjunto formado de antibioticoterapia sistêmica, repouso e compressas frias no membro afetado ${ }^{44}$. A higiene local deve começar tão logo o paciente suporte a manipulação do membro afetado. Por outro lado, o tratamento antifilarial não tem qualquer eficácia no vaso linfático já danificado pelo parasito e, consequentemente, no linfedema em si. As bases do programa de morbidade e do detalhamento do manejo clínico de pacientes portadores de linfedema em áreas endêmicas podem ser encontradas em Dreyer e Dreyer, 200046, Dreyer et al. 2006 ${ }^{47}$, Dreyer e Mattos, $2007^{48}$ e no website www.amaurycoutinho.org.br.

\section{Wolbachia: bacteria endossimbiotica filarial}

Na década de 1970, utilizando-se a microscopia eletrônica, observou-se que microrganismos semelhantes à Rickettsia parasitavam as filárias ${ }^{49,50}$. Mais tarde, demonstrou-se que esses organismos intracelulares estavam relacionados com os que eram encontrados em muitos artrópodes e foram agrupados no gênero Wolbachia ${ }^{51,52}$. Nos últimos anos, a Wolbachia filarial ganhou atenção, desde que foi mostrado que esses organismos são endossimbiontes obrigatórios, isto é, são requeridos para todos os estágios do parasito (desde os oócitos até os vermes adultos) ${ }^{53}$. Por outro lado, Rajan, em $2004^{54}$, alerta para o fato de ter sido descrito que a tetraciclina bloqueia a maturação do parasita na mudança de estágio L3 para L4 em B. malayi, sugerindo que isso ocorreria por causa do efeito anti-Wolbachia do antibiótico. De forma muito elegante, o autor mostrou que a ação antimuda das tetraciclinas se deve a uma atividade farmacológica não relacionada ao seu efeito anti-Rickettisia, uma vez que, no seu experimento, ele usou uma tetraciclina modificada quimicamente que não possui atividade anti-Wolbachia. Bandi et al., em 200152, em um trabalho importante de revisão, deram à Wolbachia um lugar de destaque, indicando-a como um novo alvo de investigação para que se possa entender os mecanismos da patogenia na doença filarial, quando seguem as ideias de Taylor et al. em 200055. Eles descrevem que extratos de $B$. malayi causam lesões inflamatórias mediadas pela reação do hospedeiro ao lipopolissacarídeo-simile existente na Wolbachia. Mecanismo similar é atribuído à lesão ocular em murinos, causada por extratos de vermes adultos e de microfilárias vivas de O. volvulus, induzida pela reação inflamatória inata aos antígenos de Wolbachia ${ }^{56}$. Assim, esse simbionte seria o alvo quimioterápico em potencial no tratamento da infecção e das diversas formas clínicas causadas por filárias. Até o momento, trabalhos têm sido publicados em oncocercose implicando a Wolbachia na doença ou no desaparecimento da microfilária, após o tratamento com antibióticos com ação anti-Wolbachia ${ }^{56-62}$. Também nas filarioses bancroftiana e brugiana, tem sido relatado 
que a terapêutica com doxaciclina poderia surgir como uma nova estratégia para o tratamento individual dos pacientes microfilarêmicos ${ }^{60,63}$. Por outro lado, ainda parece precoce que se implique a Wolbachia como o fator mais importante na patogenia das formas clínicas relacionadas à filariose linfática, como já sugerem os resultados de alguns autores ${ }^{64,65,66}$. Essa precaução é sábia, no momento em que surgem relatos mostrando que a Loa loa não parece ter quantidade suficiente de Wolbachia para permitir a sua transmissão vertical de forma eficiente ou ter algum papel na produção da microfilária ou na patogenia da doença ${ }^{67}$. Essa importante observação implica que, no caso da loíase, a resposta anti-Wolbachia não é a responsável pelo quadro clínico encontrado nessa parasitose. Dessa forma, até o momento, a indução da resposta imunológica e as manifestações clínicas da doença, assim como as severas reações adversas ocorridas com o tratamento antifilarial continuam atribuídas somente ao parasita e não ao endossimbionte ${ }^{68}$. Um outro fato importante relatado por Chirgwin et al. em $2003^{69}$, foi a demonstração da semelhança histológica do granuloma filarial produzido pela reação do hospedeiro aos vermes adultos mortos de Brugia com e sem Wolbachia. Sugere-se, assim, que a Wolbachia não parece interferir no padrão histológico/imunológico de resposta celular na formação do granuloma filarial. Esse fato constitui um argumento importante de que a Wolbachia não teria um papel relevante na patogenia da doença filarial.

A priori, devem ser criados protocolos clínicos de investigação suficientemente bem desenhados para que seja possível gerar dados científicos mais robustos que mostrem o papel da Wolbachia no aparecimento (ou exacerbação) do linfedema e da hidrocele. De forma semelhante, a estratégia para o uso de um antibiótico como a doxaciclina em larga escala (em doses recomendadas de $200 \mathrm{mg} /$ dia por 4 ou 6 semanas) $)^{70,71}$ em pacientes infectados assintomáticos, visando interromper a transmissão, precisa ser melhor avaliada antes de ser recomendada nos diversos países endêmicos, ponderando-se as consequências para a resistência microbiana, seu papel na prevenção da morbidade e o seu custo econômico.

\section{O programa global de eliminação da filariose linfática}

Em 1993, a Força Tarefa para Erradicação de Doenças elegeu a filariose linfática como uma das seis doenças infecciosas potencialmente elimináveis ${ }^{72}$. Em maio de 1997, a Assembléia Mundial da Saúde consolidou essa resolução, anunciando a eliminação global da filariose como um problema de saúde pública $^{73}$. Em julho de 1997, em Townsville, Queensland, Austrália, representantes da OMS, de seus centros colaboradores, de ministérios de saúde, de organizações não-governamentais, de academias científicas e de indústrias farmacêuticas e não-farmacêuticas estabeleceram que o controle da filariose fosse feito baseado em dois grandes pilares: a interrupção da transmissão e o controle da morbidade ${ }^{74}$. A interrupção da transmissão no planeta está planejada para 2020, com a estratégia do tratamento em massa feito anualmente, por um período de 4 a 6 anos, com os esquemas supracitados. 0 controle da morbidade se baseia na implementação de programas de prevenção dos episódios agudos bacterianos (através dos cuidados com a pele), nos portadores de linfedema, e da hidrocelectomia nos portadores de fluido em cavidade vaginal testicular.

\section{0 impacto psicossocial da doença}

Alguns estudos publicados nos últimos anos ampliaram o entendimento sobre as consequências psicossociais da filariose bancroftiana. A doença filarial ultrapassa os limites estritamente médicos e requer uma análise um pouco mais requintada dos custos psicossociais advindos das formas crônicas, tanto para os pacientes, para as famílias, quanto para o Estado.

Um importante alerta surgiu quando, oficialmente, a filariose linfática foi considerada pela OMS como a segunda causa de incapacidade permanente no mundo ${ }^{75}$ atrás dos distúrbios da afetividade, grupo que, provavelmente, também abriga milhares de pacientes com as formas mais estigmatizantes das complicações da infecção filarial ${ }^{76,77}$. Fazer a releitura do impacto dessas complicações implica mudar o foco do olhar sobre a filariose para incluir, junto dos aspectos clínicos e dos econômicos, a qualidade de vida dos seus portadores. Sob esse aspecto, estão embutidos os sofrimentos físico, emocional e segregacional que a bancroftose impõe. É preciso, portanto, ter sempre presente que as repercussões sociais não se dão apenas na redução do potencial econômico de uma pessoa, de uma família, de uma empresa ou de uma nação. Há uma magnitude médico-social e política difícil de ser estruturada, muitas vezes pelo desconhecimento do que acontece com o paciente portador de formas crônicas da filariose e de suas complicações. Enquanto constrói a sua fealdade, a elefantíase se projeta, no plano social, através da exclusão da vida produtiva de seus portadores e penetra, de forma danosa, no plano da afetividade. Fica também difícil avaliar até que ponto é a condição da pobreza que torna essa população de áreas endêmicas mais vulnerável à elefantíase ou se é a elefantíase que torna essas pessoas pobres mais pobres ainda ${ }^{48}$.

Qualquer que seja a apresentação crônica, ela coexiste com a redução da qualidade de vida expressada no engessamento dos sonhos pessoais e na fratura dos projetos de vida. As consequências individuais se abrem como um leque, mostrando o sofrimento nos variados espaços de seu mundo, resultando em seres humanos que se excluem porque são excluídos nas teias da afetividade, da sexualidade, da sobrevivência e do amorpróprio $^{78,79}$. Desse ponto para a afirmação dos conflitos, a linha divisória é muito tênue, principalmente quando a autoestima é perdida, quando o sentimento de humilhação substitui o da dignidade humana, quando não se consegue perceber que na vida há mais beleza do que a que a doença lhes toma.

Na realidade, há um custo médico-social e político difícil de ser avaliado devido à falta de metodologias sistematizadas de como a doença repercute na vida pessoal e familiar do indivíduo ${ }^{80}$. Entre esses custos de difícil quantificação, estão as perspectivas sombrias quanto à oportunidade de trabalho, ao direito ao seguro social, à moradia. Outro ponto que normalmente não é levado em consideração, e também de até mais difícil avaliação, é o aspecto emocional dos pacientes, como o sentimento de exclusão social e de vergonha por portarem as manifestações/complicações da doença. Por exemplo, um portador de quilúria pode ser confundido com um portador de síndrome da imunodeficiência adquirida, de câncer ou de tuberculose, por conta da magreza exagerada, provocada pela perda crônica de proteínas e de lipídios, carregando consigo as implicações estigmatizantes agregadas a essas doenças supracitadas. No plano socioeconômico, a perda da capacidade laborativa e a luta para 
serem incluídos no benefício previdenciário ou no amparo social/ LOAS $^{81}$ ocupam a principal preocupação com a subsistência desses pacientes. As possibilidades de trabalho são limitadas pelo mercado, que fecha suas portas, inclusive para casos de hidrocele, uma doença curável cirurgicamente ${ }^{18}$. A trajetória de progressão funcional no emprego é fragilizada ou totalmente desfeita com a progressão da doença nos portadores do dano linfático: episódio agudo bacteriano (faltas ao trabalho), edema, recorrência dos episódios agudos (novas faltas), culminando com a demissão. Dessa forma, a perda do emprego representa mais do que uma perda profissional. É, na verdade, uma desvinculação de uma rede social que foi conquistada no universo de trabalho. Portanto, já não se tem mais dúvida de que a doença é impactante nas diversas esferas da vida do portador, embora tal impacto ainda não esteja quantificado em valor monetário para a grande maioria delas $76,78,79$.

O Brasil é, hoje, membro do grupo de países classificados como de alto índice de desenvolvimento humano ${ }^{82}$ e, paradoxalmente, ainda está na lista dos países endêmicos para filariose linfática oficialmente reconhecida pela $\mathrm{OMS}^{1}$. Sob o prisma da filariose, a repercussão psicossocial existente não o torna diferente de países que estão classificados com o mais baixo IDH e que são também endêmicos, como Serra Leoa, Niger e outros do continente africano. $O$ que 0 assemelha também é a convivência diária de sua população com o vetor da infecção bancroftiana, - Culex quinquefasciatus. A ocorrência da filariose pode servir de termômetro para medir as condições de saúde pública em que se vive. Reflete as moradias subumanas, que obrigam seus habitantes a conviverem com as próprias excretas ${ }^{83}$. Espelha a dificuldade de acesso aos bens públicos, como água e saneamento básico. A ocorrência da filariose é um indicador do abandono social em função da fragilidade das políticas públicas. Talvez a reflexão sobre como esses fatores interagem e se expressam no cotidiano é que deva nortear qualquer ação de promoção e de prevenção da saúde e melhoria da qualidade de vida. Mudar paradigmas requer não somente aprender com novos conceitos, mas também instituir mudanças reais que são exigidas eticamente após ter tido acesso ao conhecimento disponibilizado pela ciência.

\section{Os Clubes da Esperança: uma nova perspectiva para os pacientes}

A exclusão familiar e/ou social, quando associada à ideia de que a progressão da doença é inevitável, produz nos pacientes das áreas endêmicas sentimentos de dependência, passividade e desespero. A experiência sugere que essa realidade pode ser transformada através da implementação dos programas chamados de Clubes da Esperança. Em 1993, foi criado em Recife, Brasil, reuniões nas quais pacientes compartilham experiência, motivando-se uns aos outros para voltarem a participar como membros ativos da sociedade. Através da participação e do apoio em grupo, os pacientes são conscientizados de que o sucesso ou não do seu tratamento depende também deles e que podem fazer uso dos recursos que cada um possui, sejam estes físicos, emocionais ou sociais. A criação de Clubes da Esperança pode contribuir, a baixo custo, como terapia coadjuvante importante na melhoria da qualidade de vida dos portadores de linfedema e de quilúria. Eles sentem que não estão sós e, através de ações especializadas e do trabalho em grupo, podem ter a chance de readquir o potencial para o trabalho produtivo, realizando também mudanças substancialmente positivas dentro de suas comunidades, agindo, assim, como amplificadores do processo $47,48,84$.

\section{Recomendação final}

$\mathrm{Na}$ condução do paciente portador de linfedema com história epidemiológica de risco de ter adquirido infecção filarial no passado, é importante ressaltar aos profissionais de saúde que o parasito não interfere na possibilidade de ocorrência de linfedema primário (esporádico ou não) ou de outras etiologias. Assim, recomenda-se que, no diagnóstico diferencial, seja incluída essa possibilidade, no sentido de melhor assistir ao paciente em relação ao seu prognóstico, à necessidade de aconselhamento genético ou à necessidade de um manejo clínico e/ ou cirúrgico mais complexo em centros especializados.

\section{Agradecimentos}

Os autores agradecem a Patricia Dreyer e David Addiss pelas valiosas sugestões no manuscrito original; ao apoio financeiro e logístico da Organização Não-governamental Amaury Coutinho para Doenças Endêmicas e Tropicais na confecção do presente manuscrito.

\section{Conflito de interesse: não há}

\section{Summary}

\section{PaRAdIGM SHIFT IN BANCROFTIAN FILARIASIS}

The way a particular subject is understood changes over time as a result of scientific research. In most cases, these changes are minor, with limited effect on the overall knowledge on the subject. Sometimes, however, revolutionary changes occur and not only modify the understanding of the subject but open perspectives that can trigger new interpretations and new ways for expansion of scientific knowledge. The studies of Gregor Johann Mendel were a good example. They led to discovery of the laws of inheritance which, in turn, have revolutionized biology and provided the foundation for genetics. In certain situations, changes not only alter ways of thinking, but have practical implications, also improving the quality of life for many people. In his book The Structure of Scientific Revolutions, Thomas Kuhn refers to discontinuities in scientific development as a "change of paradigm", a term now used in a generic manner to describe a profound changes in our reference points. For lymphatic filariasis the old paradigm stated that Wuchereria bancrofti at the adult stage causes lymphatic vessel obstruction, triggering an inevitable immune response in predisposed individuals and leading to elephantiasis. This has been replaced by a new paradigm, which offers hope that $W$. bancrofti infection does not necessarily predispose to the disfiguring outward manifestation of lymphatic dysfunction. Repeated secondary bacterial infections (erysipela-like) are now recognized as the most important factor for initiation and progression of chronic lymphedema in individuals living in filariasis-endemic areas. Most inhabitants of endemic communities can prevent and minimize the acute bacterial episodes by regular use of soap and water, the simplest form of hygiene already well known to human beings. [Rev Assoc Med Bras 2009; 55(3): 355-62]

KeY WORDS: Bancroftian filariasis. Wuchereria bancrofti. Wolbachia. Lymphedema. Paradigma. Hope club. 


\section{REFERÊNCIAS}

1. World Health Organization. Global Programme to Eliminate Lymphatic Filariasis. Wkly Epidemiol Rec. 2005;80:202-12. [cited 2008 Jul 16]. Available from: http://www.who.int/wer/2005/wer8023.pdf.

2. Fontes G, Rocha EMM, Brito AC, Antunes CMF. Lymphatic filariasis in brazilian urban area (Maceió, Alagoas). Mem Inst Oswaldo Cruz. 1998;93:705-10.

3. Medeiros Z, Gomes J, Beliz F, Coutinho A, Dreyer P, Dreyer G. Screening of army soldiers for Wuchereria bancrofti infection in metropolitan Recife region, Brazil: implications for epidemiologic surveillance. Trop Med Int Health. 1999;4:499-505.

4. Medeiros Z, Dreyer G, Andrade L, Pires ML, Mendes J, Pimentel R. Wuchereria bancrofti microfilarial density of autochthonous cases and natural Culex infectivity rates in Northeast Brazil. J Trop Med Hyg. 1992;95:214-7.

5. Fontes G, Braun RF, Fraiha Neto H, Vieira JBF, Padilha SS, Rocha RC, et al. Filariose linfática em Belém, Estado do Pará, Norte do Brasil e a perspectiva de eliminação. Rev Soc Bras Med Trop. 2005;38:131-6.

6. Michael E, Bundy DAP, Grenfell BT. Re-assessing the global prevalence and distribution of lymphatic filariasis. Parasitology. 1996;112:409-28.

7. Jamal S, Pani SP. Long term follow up of filarial edema with conservative medical management. Lymphology. 2000;33(Suppl):144-6.

8. Ramaiah KD, Das PK, Michael E, Guyatt $H$. The economic burden of lymphatic filariasis in India. Parasitol Today. 2000;16:251-3.

9. Dreyer G, Dreyer P, Piessens W. Extralymphatic disease due to bancroftian filariasis. Braz J Med Biol Res. 1999;32:1467-72.

10. Freedman DO, de Almeida Filho PJ, Besh S, Maia e Silva MC, Braga C, Maciel A. Lymphoscintigraphic analysis of Iymphatic abnormalities in symptomatic and asymptomatic human filariasis. J Infect Dis. 1994;170:927-33.

11. Marchetti F, Piessens FW, Medeiros Z, Dreyer G. Abnormalities of the leg lymphatics are not specific for bancroftian filariasis. Trans R Soc Trop Med Hyg. 1998;92:650-2

12. Amaral F, Dreyer G, Figueredo-Silva J, Norões J, Cavalcanti A, Samico SF, et al. Live adult worms detected by ultrasonography in human bancroftian filariasis. Am J Trop Med Hyg. 1994:50:753-7.

13. Norões J, Addiss D, Santos A, Medeiros Z, Coutinho A, Dreyer G. Ultrasonographic evidence of abnormal lymphatic vessels in young men with adult Wuchereria bancrofti infection in the scrotal area. J Urol. 1996;156:409-12.

14. Figueredo-Silva J, Norões J, Cedenho A, Dreyer G. The histopathology of bancrftian filariasis revisited: the role of the adult worm in the lymphatic-vessel disease. Ann Trop Med Parasitol. 2002;96:531-41.

15. Dreyer G, Norões J, Figueredo-Silva J, Piessens WF. Pathogenesis of lymphatic disease in bancroftian filariasis: a clinical perspective. Parasitol Today. 2000; 16:544-8.

16. Dreyer G, Medeiros Z, Netto MJ, Leal NC, De Castro LG, Piessens WF. Acute attacks in the extremities of persons living in an area endemic for bancroftian filariasis: differentiation of two syndromes. Trans R Soc Trop Med Hyg. 1999;93:413-7.

17. Olszewski WL, Jamal S, Manokaran G, Pani S, Kumaraswami V, Kubicka U, et al. Bacteriologic studies of skin, tissue fluid, lymph, and lymph nodes in patients with filarial Iymphedema. Am J Trop Med Hyg. 1997;57:7-15.

18. Norões J, Addiss D, Cedenho A, Figueredo-Silva J, Lima G, Dreyer G. Pathogenesis of filarial hydrocele: risk associated with intrascrotal nodules caused by death of adult Wuchereria bancrofti. Trans R Soc Trop Med Hyg. 2003;97:561-6.

19. Dreyer G, Addiss D, Roberts J, Norões J. Progression of Iymphatic vessel dilatation in the presence of living adult Wuchereria bancrofti. Trans R Soc Trop Med Hyg. 2002;96:157-61.

20. Norões J, Dreyer G, Santos A, Mendes VG, Medeiros Z, Addiss D. Assessment of the efficacy of diethylcarbamazine on adult Wuchereria bancrofti in vivo. Trans R Soc Trop Med Hyg. 1997;91:78-81.

21. Gyapong JO, Webber RH, Morris J, Bennett S. Prevalence of hydrocele as a rapid diagnostic index for lymphatic filariasis. Trans R Soc Trop Med Hyg. 1998;92:40-3.

22. Dreyer G, Pimentel A, Medeiros Z, Béliz F, Moura I, Coutinho A, et al. Studies on the periodicity and intravascular distribution of Wuchereria bancrofti microfilariae in paired samples of capillary and venous blood from Recife, Brazil. Trop Med Int Health. 1996;1:264-72.

23. Dreyer G, Santos A, Norões J, Addiss D. Proposed panel of diagnostic criteria, including the use of ultrasound, to refine the concept of "endemic normals" in Iymphatic filariasis. Trop Med Int Health. 1999;4:575-9.

24. Dreyer G, Figueredo-Silva J, Carvalho K, Amaral F, Ottesen EA. Lymphatic filariasis in children: adenopathy and its evolution in two young girls. Am J Trop Med Hyg. 2001;65:204-7.

25. Dreyer G, Lins R, Norões J, Rizzo JA, Figueredo-Silva J. Sensitivity of the immunochromatographic card test relative to detection of adult Wuchereria bancrofti worms by ultrasound. Am J Trop Med Hyg. 2008;78:28-34.

26. Addiss DG, Louis-Charles J, Wendt JM. Epidemiology of "acute attacks" among patients in a treatment program for filariasis-associated lymphedema of the leg, Leogane, Haiti. J Am Soc Trop Med Hyg. 1999;61(Suppl 3):320.
27. Dreyer G, Norões J, Amaral F, Nen A, Medeiros Z, Coutinho A, et al. Direct assessment of the adulticidal efficacy of single dose ivermectin in bancroftian filariasis. Trans R Soc Trop Med Hyg. 1995;89:441-3.

28. Dreyer G, Addiss D, Norões J, Amaral F, Rocha A, Coutinho A. Ultrasonographic assessment of the adulticidal efficacy of repeat high-dose ivermectin in bancroftian filariasis. Trop Med Int Health. 1996;1:427-32.

29. Ottesen EA, Duke BO, Karam M, Behbehani K. Strategies and tools for the control/elimination of lymphatic filariasis. Bull World Health Organ. 1997;75:491-503.

30. Dreyer G, Ottesen EA, Galdino E, Andrade L, Rocha A, Medeiros Z, et al. Renal abnormalities in microfilaremic patients with bancroftian filariasis. Am J Trop Med Hyg. 1992;46:745-51.

31. Dreyer G, Norões J, Figueredo-Silva J. Elimination of Iymphatic filariasis as a public health problem. New insights into the natural history and pathology of bancroftian filariasis: implications for clinical management and filariasis control programs. Trans R Soc Trop Med Hyg. 2000;94:594-6.

32. Figueredo-Silva J, Dreyer G. Bancroftian filariasis in children and adolescents: clinical pathological observations in 22 cases from an endemic area. Ann Trop Med Parasitol. 2005;99:759-69.

33. Norões J, Addiss D, Amaral F, Coutinho A, Medeiros Z, Dreyer G. Occurrence of living adult Wuchereria bancrofti in the scrotal area of men with microfilaraemia. Trans R Soc Trop Med Hyg. 1996;90:55-6.

34. Reddy GS, Das LK, Pani SP. The preferential site of adult Wuchereria bancrofti: an ultrasound study of male asymptomatic microfilaria carriers in Pondicherry, India. Natl Med J India. 2004;17:195-6.

35. Dreyer G, Brandão AC, Amaral F, Medeiros Z, Addiss D. Detection by ultrasound of living adult Wuchereria bancrofti in the female breast. Mem Inst Oswaldo Cruz. 1996;91:95-6.

36. Mand S, Debrah A, Batsa L, Adjei O, Hoerauf A. Reliable and frequent detection of adult Wuchereria bancrofti in Ghanaian women by ultrasonography. Trop Med Int Health. 2004;9:1111-4.

37. Webster EH. Filariasis among white immigrants in Samoa. U S Nav Med Bull. 1946;46:186-92.

38. Trent SC. Reevaluation of World War II veterans with filariasis acquired in the South Pacific. Am J Trop Med Hyg. 1963;12:877-87.

39. Chen TT. Demonstration of macrofilaricidal action of Hetrazan, antimony and arsenic preparations in man. Chin Med J. 1964;83:625-40.

40. Fasana F. The pathogenesis and pathology of hydrocele in the tropical countries. In: Fasana F, editor. Hydrocele in the temperate and tropical countries. Florida: CRC Press; 1983. v.2, p.31-45.

41. Dreyer G, Mattos D, Norões J. Quilúria. Rev Assoc Med Bras. 2007;53:460-64.

42. Shenoy RK, Sandhya K, Suma TK, Kumaraswami V. A preliminary study of filariasis related acute adenolymphangitis with special reference to precipitating factors and treatment modalities. Southeast Asian J Trop Med Public Health. 1995;26:301-5.

43. Shenoy RK, Kumaraswami V, Suma TK, Rajan K, Radhakuttyamma G. A double-blind, placebo-controlled study of the efficacy of oral penicillin, diethylcarbamazine or local treatment of the affected limb in preventing acute adenolymphangitis in lymphoedema caused by brugian filariasis. Ann Trop Med Parasitol. 1999;93:367-77.

44. Dreyer G, Addiss D, Dreyer P, Noroes J, editors. Basic lymphoedema management: treatment and prevention of problems associated with lymphatic filariasis. Hollis: Hollis Publishing; 2002.

45. Dreyer G, Addiss D, Gadelha P, Lapa E, Williamson J, Dreyer A. Interdigital skin lesions of the lower limbs among patients with lymphoedema in an area endemic for bancroftian filariasis. Trop Med Int Health. 2006;11:1475-81.

46. Dreyer $G$, Dreyer P. Bases para o tratamento da morbidade em áreas endêmicas de filariose. Rev Soc Bras Med Trop. 2000;33:217-21.

47. Dreyer G, Norões J, Mattos D. Terapia complementar em área endêmica de filariose bancroftiana, pelos Clubes da Esperança. Rev Soc Bras Med Trop. 2006;39:365-9.

48. Dreyer G, Mattos D. A prevenção da elefantíase em áreas endêmicas de bancroftose: realidade ou utopia? Prat Hosp. 2007;49:94-6.

49. McLaren DJ, Worms MJ, Laurence BR, Simpson MG. Micro-organisms in filarial larvae (Nematoda). Trans R Soc Trop Med Hyg. 1975;69:509-14.

50. Kozek WJ, Marroquin HF 1977. Intracytoplasmic bacteria in Onchocerca volvulus. Am J Trop Med Hyg. 1977;26:663-78.

51. Sironi M, Bandi C, Sacchi L, Di Sacco B, Damiani G, Genchi C. Molecular evidence for a close relative of the arthropod endosymbiont Wolbachia in a filarial worm. Mol Biochem Parasitol. 1995;74:223-7.

52. Bandi C, Trees AJ, Brattig NW. Wolbachia in filarial nematodes: evolutionary aspects and implications for the pathogenesis and treatment of filarial diseases. Vet Parasitol. 2001;98:215-38.

53. Taylor MJ, Hoerauf A. A new approach to the treatment of filariasis. Curr Opin Infect Dis. 2001;14:727-31.

54. Rajan TV. Relationship of anti-microbial activity of tetracyclines to their ability to block the L3 to L4 molt of the human filarial parasite Brugia malayi. Am J Trop Med Hyg. 2004;71:24-8. 
55. Taylor MJ, Cross HF, Bilo K. Inflammatory responses induced by the filarial nematode Brugia malayi are mediated by lipopolysaccharide-like activity from endosymbiotic Wolbachia bacteria. J Exp Med. 2000;191:1429-36.

56. Saint André A, Blackwell NM, Hall LR, Hoerauf A, Brattig NW, Volkmann L, et al. The role of endosymbiotic Wolbachia bacteria in the pathogenesis of river blindness. Science. 2002;295:1892-5.

57. Brattig NW, Rathjens U, Ernst M, Geisinger F, Renz A, Tischendorf FW. Lipopolysaccharide-like molecules derived from Wolbachia endobacteria of the filarial Onchocerca volvulus are candidate mediators in the sequence of inflammatory and antiinflammatory responses of human monocytes. Microbes Infect. 2000;2:1147-57.

58. Brattig NW, Büttner DW, Hoerauf A. Neutrophil accumulation around Onchocerca worms and chemotaxis of neutrophils are dependent on Wolbachia endobacteria. Microbes Infect. 2001;3:439-46.

59. Hoerauf A, Mand S, Adjei O, Fleischer B, Büttner DW. Depletion of Wolbachia endobacteria in Onchocerca volvulus by doxycycline and microfilaridermia after ivermectin treatment. Lancet. 2001;357:1415-6.

60. Hoerauf A, Mand S, Fischer K, Kruppa T, Marfo-Debrekyei Y, Debrah AY, et al. Doxycycline as a novel strategy against bancroftian filariasis-depletion of Wolbachia endosymbionts from Wuchereria bancrofti and stop of microfilaria production. Med Microbiol Immunol. 2003;192:211-6

61. Keiser PB, Reynolds SM, Awadzi K, Ottesen EA, Taylor MJ, Nutman TB. Bacterial endosymbionts of Onchocerca volvulus in the pathogenesis of postreatment reactions. J Infect Dis. 2002;185:805-11.

62. Fischer $\mathrm{P}$, Bonow I, Büttner DW, Kamal IH, Liebau $\mathrm{E}$. An aspartate aminotransferase of Wolbachia endobacteria from Onchocerca volvulus recognized by IgG1 antibodies from residents of endemic areas. Parasitol Res. 2003;90:38-47

63. Supali T, Djuardi Y, Pfarr KM, Wibowo H, Taylor MJ, Hoerauf A, et al. Doxycycline treatment of Brugia malayi-infected persons reduces microfilaremia and adverse reactions after diethylcarbamazine and albendazole treatment. Clin Infect Dis. 2008:46:1385-93.

64. Punkosdy GA, Dennis VA, Lasater BL, Tzertzinis G, Foster JM, Lammie PJ. Detection of serum IgG antibodies specific for Wolbachia surface protein in rhesus monkeys infected with Brugia malayi. J Infect Dis. 2001:184:385-9.

65. Taylor MJ, Cross HF, Ford L, Makunde WH, Prasad GBKS, Bilo K. Wolbachia bacteria in filarial immunity and disease. Parasite Immunol. 2001;23:401-9.

66. Taylor MJ. Wolbachia in the inflammatory pathogenesis of humam filariasis. Ann NY Acad Sci. 2003;990:444-9.

67. Brouqui P, Fournier PE, Raoult D. Doxycycline and eradication of microfilaremia in patients with loiasis. Emerg Infect Dis. 2001;7(Suppl 3):604-5.

68. Büttner DW, Wanji S, Bazzocchi C, Bain O, Fischer P. Obligatory symbiotic Wolbachia endobacteria are absent from Loa loa. Filaria J. 2003;2:10.

69. Chirgwin SR, Coleman SU, Porthouse KH, Nowling JM, Punkosdy GA, Klei TR. Removal of Wolbachia from Brugia pahangi is closely linked to worm death and fecundity but does not result in altered lymphatic lesion formation in Mongolian gerbils (Meriones unguiculatus). Infect Immun. 2003;71:6986-94.
70. Debrah AY, Mand S, Marfo-Debrekyei Y, Batsa L, Pfarr K, Buttner M, et al. Macrofilaricidal effect of 4 weeks of treatment with doxycycline on Wuchereria bancrofti. Trop Med Int Health. 2007;12:1433-41.

71. Debrah AY, Mand S, Specht S, Marfo-Debrekyei Y, Batsa L, Pfarr K, et al. Doxycycline reduces plasma VEGF-C/sVEGFR-3 and improves pathology in Iymphatic filariasis. Plos Plathog. 2006;2:829-43.

72. Centers for Disease Control and Prevention (CDC). Recommendations of the International Task Force for Disease Eradication. MMWR Recomm Rep. 1993;42:1-38. [cited 2008 Jul 16]. Available from: http://www.cdc.gov/ mmwr/PDF/rr/rr4216.pdf.

73. World Health Organization. Resolution WHA50.29: elimination of Iymphatic filariasis as a public health problem. Fiftieth World Health Assembly, Geneva, 5-14 May 1997: resolutions and decisions; annexes. Geneva: World Health Organization. 1997 (WHA50/1997/REC/1). [cited 2008 Jul 16]. Available from: http://www.who.int/lymphatic_filariasis/resources/WHA_50 29.pdf.

74. Seim AR, Dreyer G, Addiss D. Controlling morbidity and interrupting transmission: twin pillars of lymphatic filariasis elimination. Rev Soc Bras Med Trop. $1999 ; 32: 325-8$

75. World Health Organization. The World Health Report 1995 - Bridging the Gaps. Geneva: World Health Organization. Available from: http://www.who. int/whr/1995/en/index.html. [cited 2008 Jul 16].

76. Mattos D, Dreyer G. Elefantíase em área de filariose bancroftiana: o lado humano da doença. Rev Patol Trop. 2006;35:117-24.

77. Dreyer G, Mattos D. Perspectives of elephantiasis in an endemic area of Brazil. J Lymph. 2007;2:24-31.

78. Dreyer G, Norões J, Addiss D. The silent burden of sexual disability associated with Iymphatic filariasis. Acta Trop. 1997;63:57-60.

79. Dreyer G, Norões J. Filariose bancroftiana: o reverso das alterações orgânicas. J Bras Psiquiatr. 1998;47:227-31.

80. Dreyer G, Mattos D, Norões J. Filariose bancroftiana. In: Coura JR, editor. Dinâmica das doenças infecciosas e parasitárias. Rio de Janeiro: Guanabara Koogan; 2005. p.1087-106.

81. Lei Orgânica da Assistência Social (LOAS), Pub. L. No. 8742. Diário Oficial da União (08/dez/1993).

82. United Nations Development Programme (UNDP). Statistics of the Human Development Reports. 2007/2008 Human Development Index rankings. [cited 2008 Jul 16]. Available from: http://hdr.undp.org/en/statistics/.

83. Mattos D, Mota S, Dreyer G. Aspectos da realidade social de crianças e adolescentes atendidos em serviço de referência para filariose bancroftiana - Recife, Estado de Pernambuco. Rev Bras Med Trop. 2008;41:29-35.

84. Dreyer G, Addiss D. Hope clubs: new strategy for lymphatic filariasis endemic areas. Trans R Soc Trop Med Hyg / Bull Trop Med Int Health. 2000;8:8.

Artigo recebido: $27 / 07 / 08$ Aceito para publicação: 18/09/08 